\title{
Impaired pulmonary status in cystic fibrosis adults with two mutated $M B L-2$ alleles
}

\author{
J.C. Davies*\#, M.W. Turner", N. Klein ${ }^{\Uparrow}$, and the London MBL CF Study Group \\ The London MBL CF Study Group: C. Booth, M. Johnson, N. Shen, K. Fidler, S. Sharma, J. Burgess, A. Bush, D.M. Geddes, E.W.F.W. Alton.
}

Impaired pulmonary status in cystic fibrosis adults with two mutated MBL-2 alleles. J.C. Davies, M.W. Turner, N. Klein, and the London MBL CF Study Group. C) ERS Journals Ltd 2004.

ABSTRACT: Mannose-binding lectin has recently been identified as a modifier of severity in cystic fibrosis, although studies have produced differing results and the mechanism of action remains unclear.

The current authors have studied large cohorts of adults $(n=298)$ and children $(n=260)$ to explore this apparent relationship further.

Adults with two structural mutations, but not heterozygotes, had significantly reduced lung function and oxygen saturations, more frequent hospital admissions and raised systemic inflammatory markers. This was not related to increased rates of infection with Pseudomonas aeruginosa, and there was no increased susceptibility to Burkholderia cepacia. None of these findings was mirrored in the paediatric cohort.

In conclusion, severe mannose-binding lectin deficiency appears to be detrimental to cystic fibrosis adults, although heterozygotes are not affected. It is suggested that this is not related to impaired complement-mediated bacterial killing, and a link with the host inflammatory response is hypothesised. If mannose-binding lectin replacement is developed as a new approach to treatment for this disease, the present study would suggest that the small group of severely deficient patients with two structural mutations may be the group to benefit.

Eur Respir J 2004; 24: 798-804.
*Dept of Paediatric Respiratory Medicine Royal Brompton Hospital, "Dept of Gene Therapy, Imperial College, and Immunobiology Unit, Institute of Child Health, University College, London, UK.

Correspondence: J.C. Davies, Dept of Paediatric Respiratory Medicine, Royal Brompton Hospital, Sydney St, London, SW3 6NP, UK Fax: 442073518340

E-mail: j.c.davies@imperial.ac.uk

Keywords: Collectin, inflammation, lung function, modifier gene, phenotype, polymorphism

Received: May 102004

Accepted after revision: July 152004

This work was supported by the Cystic Fibrosis Research Trust, by a Wellcome Trust Senior Clinical Fellowship (E.W.F.W. Alton), and a Wellcome Trust Clinical Fellowship (K. Fidler). Research at the Institute of Child Health and Great Ormond Street for Children National Health Service (NHS) Trust benefits from research and development funding received from the UK NHS executive. Consumables for this study were funded in part by NatImmune $\mathrm{A} / \mathrm{S}$, Copenhagen, Denmark. M.W. Turner and N. Klein are consultants for this company, which is developing a recombinant form of mannose-binding lectin.
Most of the morbidity and mortality in cystic fibrosis (CF) relates to lung disease, characterised by chronic bacterial infection and a sustained and deleterious inflammatory response [1]. However, disease severity is highly variable, even in subjects with identical cystic fibrosis transmembrane regulator $(C F T R)$ gene mutations, leading investigators to search for modifier genes, such as alternative ion channels or proteins involved in host defence and inflammation. A collectin, mannose-binding lectin (MBL), has recently been identified as one such modifier [2,3]. Together with the mucociliary escalator, professional phagocytes and other proteins (lysozyme, lactoferrin, defensins, complement), collectins form the first line of airway defence, before the adaptive immune systems come into play. In its functional oligomeric form, MBL binds to carbohydrate arrays on the surface of microorganisms, initiating complement-mediated lysis and acting as an opsonin to facilitate phagocyte function [4]. The protein also influences the inflammatory response in a complex and incompletely understood manner [5].
Three polymorphisms have been identified within the structural region of the encoding gene, $M B L-2[6,7]$. Mutant proteins are incapable of forming high-order oligomers and possess shortened half-lives. Individuals with two mutations have profoundly reduced levels of MBL, whilst intermediate levels are observed in heterozygotes. Polymorphisms have also been identified within the promoter region of $M B L-2$, in linkage disequilibrium with the structural mutations, and one of these $(\mathrm{X} / \mathrm{Y})$ significantly affects protein levels [8]. As heterozygotes comprise $>30 \%$ of the healthy population, MBL is likely, in general, to play only an adjunctive role in host defence. However, low protein levels relate to an increased risk of a variety of infections [9-11], including those of the respiratory tract [12]. The detection of MBL in human nasopharyngeal secretions [13] provides further evidence for a role of the protein in respiratory defence.

Two previous studies reported that $M B L-2$ was a modifier of lung disease in $\mathrm{CF}$, although these reports conflicted on whether the effect was limited to the homozygous-deficient 
state seen in only $3-4 \%$ of individuals [3] or whether it was also seen in the $30 \%$ of the population carrying a single mutation [2]. This differentiation would have important implications for the development of MBL replacement as a treatment for $\mathrm{CF}$. In an attempt to explore this further, the current authors have correlated $M B L-2$ haplotype status with clinical markers of severity in a large cohort of both adults and children with $\mathrm{CF}$.

\section{Methodology}

\section{Patients and clinical data}

Patients were recruited from the adult and paediatric $\mathrm{CF}$ clinics at the Royal Brompton Hospital, London, UK, between 2000 and 2002. Samples were obtained at the time of a routine blood test whenever possible. Clinical data were obtained from the clinical databases, patients' hospital notes and computerised microbiology reports. Forced expiratory volume in one second (FEV1) and forced vital capacity (FVC) were obtained from annual lung function laboratory records, corrected for sex, age and height, and expressed as a percentage of predicted normal values [14]. For the paediatric cohort, lung function was recorded for specific ages for purposes of standardisation $(6-7,8-9,10-11,12-13$ and 14-16 yrs). For adults, annual values were recorded, where available, from 1990-2002. Annual rate of decline was calculated for all subjects with two or more values after linear regression of all available data. For the adult patients, transcutaneous oxygen saturation with the patient breathing room air was obtained at the annual visit, and a record of the requirement for supplementary oxygen was made. Microbiological data included the presence of any samples positive for Psuedomonas aeruginosa and Burkholderia cepacia. In the paediatric group only, data were also available for Stenotrophomonas maltophilia, Staphylococcus aureus and Aspergillus fumigatus. C-reactive protein (CRP) and white cell counts were reported by the clinical biochemistry and haematology laboratories of the Royal Brompton Hospital, respectively. A further 38 blood samples were analysed from B. cepacia-infected patients from three other UK CF centres. No further clinical data were obtained on these subjects.

Clinical parameters were compared between three $M B L-2$ haplotype groups (wild-type homozygous, heterozygous and homozygous/compound heterozygous deficient). Subsequently, each adult patient with two copies of the mutant allele was retrospectively matched with two adults with no $M B L-2$ mutations for further comparison. Matching was performed on the basis of age (closest within $5 \mathrm{yrs}$ ), sex and $C F T R$ genotype ( $\Delta \Delta, \Delta$ other or other/other). If more than two matches were available, the patient was paired with the nearest two subjects in a randomly generated list.

The study was approved by the ethics committees of the Royal Brompton Hospital, Harefield Hospital, and the National Heart and Lung Institute and participating centres, and all subjects, parents or carers gave informed consent for participation.

\section{Sample analysis}

Preparation and amplification of genomic DNA and $M B L-2$ haplotyping were performed as previously described $[15,16]$. Genotyping was performed separately for the exon-1 mutations and the promoter polymorphisms. In both cases, a synthetic DNA molecule (universal heteroduplex generator (UHG)) was constructed, spanning the region of interest and containing insertions, deletions and/or substitutions. The combined use of these UHGs (kindly provided by $\mathrm{N}$. Wood, University of Bristol, Bristol, UK) permitted the detection of all possible known mutations. MBL levels in serum were determined by a symmetrical sandwich ELISA, using a kit from the State Serum Institute, Copenhagen, Denmark, according to the manufacturer's instructions.

\section{Statistical analysis}

Differences between haplotype groups were analysed by one-way ANOVA with Tukey's post hoc comparisons or by Chi-squared analysis. Fisher's exact test was used for groups containing fewer than five values. Data are presented as mean \pm SEM. The null hypothesis was rejected at $\mathrm{p}<0.05$.

\section{Results}

\section{Patient demographics}

Blood samples were available from 298 (57\% male) adult subjects aged $29.7 \pm 0.5$ yrs. CFTR genotype data were available on $269(90.3 \%)$ of these, as follows: $\Delta / \Delta(48 \%), \Delta$ other $(44.6 \%)$, and other/other $(7.4 \%)$. A total of 260 children ( $48 \%$ male) with a mean age of $8.5 \pm 0.3$ yrs were included. In 228 children, CFTR genotype data were available, as follows: $\Delta / \Delta(58.8 \%), \Delta$ other $(34.6 \%)$ and other/other $(6.6 \%)$.

\section{Mannose-binding lectin-2 haplotypes and serum levels}

Both MBL serum levels and $M B L-2$ haplotype data were available in 522 cases; in 7 cases, only haplotypes were obtained and, in 25 , only protein levels were available. The frequencies of mutations in both exon 1 (fig. 1a) and the promoter region did not differ between adults and children, and were similar to those observed in other studies of both healthy subjects [17] and patients with CF [2]. Overall, 61.1\% had no structural mutations (conventionally designated A/A), $35.2 \%$ were heterozygous (designated $\mathrm{A} / \mathrm{O}$ ) and $3.8 \%$ were either homozygous or compound heterozygous (both designated $\mathrm{O} / \mathrm{O}$ ). In patients with structural gene mutations, the $\mathrm{B}$ allele was found on $71 \%$ of chromosomes, with the other mutations occurring less frequently (C: 11\%, D: 18\%). The low-expressing X-promoter polymorphism was found in association with $30.6 \%$ of wild-type structural alleles.

Serum MBL level was significantly related to $M B L-2$ haplotype (fig. $1 \mathrm{~b} ; \mathrm{p}<0.001$ ). The highest protein levels were seen in patients with two wild-type structural alleles, and the lowest in individuals with two structural mutations and in heterozygotes with the X-promoter mutation. Levels were similar in adults and children, with the exception that adults with the YA/YA haplotype had significantly $(\mathrm{p}<0.001)$ higher levels $\left(3858 \pm 221 \mathrm{ng} \cdot \mathrm{mL}^{-1}\right)$ than those observed in the paediatric cohort $\left(2959 \pm 139 \mathrm{ng} \cdot \mathrm{mL}^{-1}\right)$. As a result, the adult homozygous-sufficient A/A subjects had significantly $(\mathrm{p}<0.05)$ higher levels than the A/A children.

\section{Lung function, infection and inflammatory markers}

Different results were observed with respect to the adults and paediatric subjects, and these groups are therefore presented separately.

Adults. Lung function. A mean of $6.1 \pm 0.2$ lung function recordings (range 1-13) was available on 273 haplotyped 

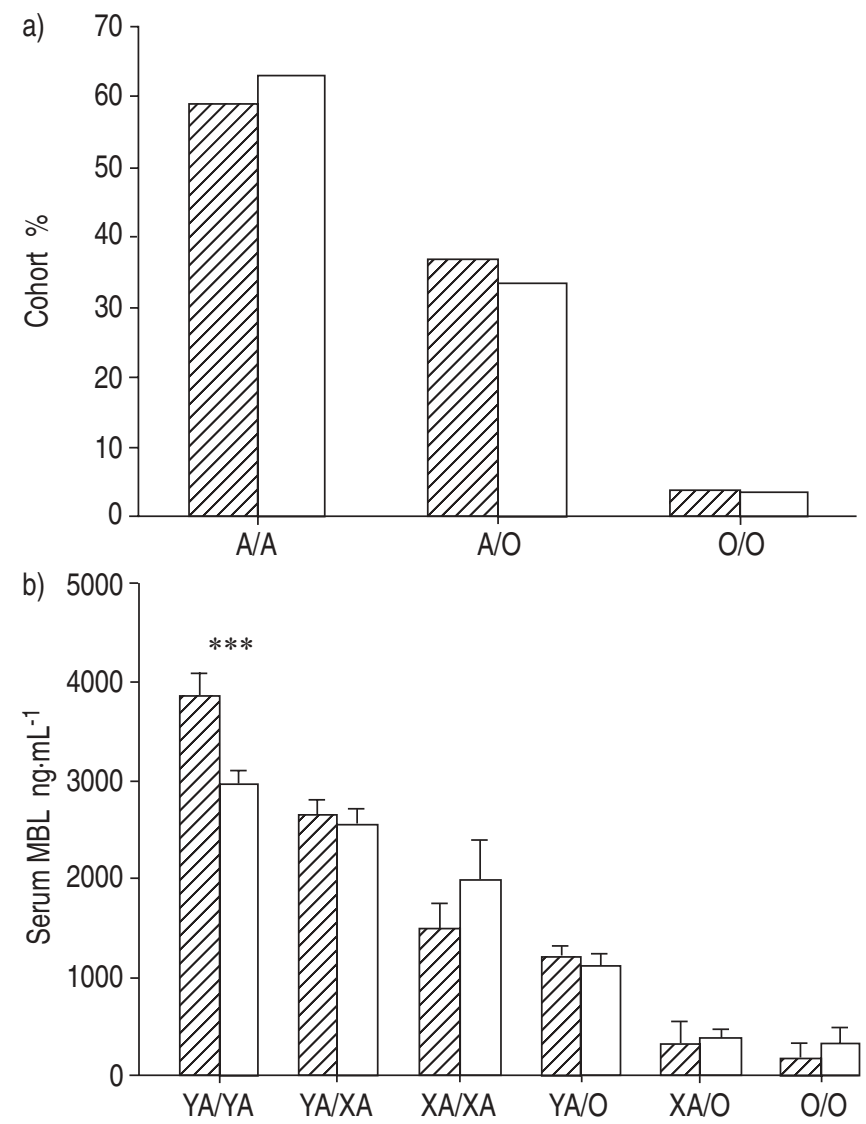

Fig. 1.-a) The frequency of mannose-binding lectin $(M B L)-2$ gene structural mutations was similar amongst the adult $(\mathbb{Z})$ and paediatric ( $\square$ ) cohorts. A represents the wild-type allele and $\mathrm{O}$ any mutation (B, $\mathrm{C}$, or D). b) MBL serum level was significantly related to $M B L-2$ haplotype $(\mathrm{p}<0.001)$. Serum levels in each haplotype group were similar in the adult and paediatric groups, with the exception of the YA/YA group, in which levels were significantly higher in the adults. Data are presented as mean \pm SEM. ${ }^{* * *}: \mathrm{p}<0.001$.

adults over a period of $6.5 \pm 0.2$ yrs. Mean FEV1 was significantly associated with $M B L-2$ haplotype, the lowest values being observed in individuals possessing two structural mutations (fig. 2a; ANOVA $\mathrm{p}<0.05$ ). A similar pattern was seen for mean FVC (fig. 2a). Neither parameter was reduced significantly in heterozygotes. No effect was seen of the low-expressing X-promoter polymorphism on lung function in either the homozygous-sufficient or heterozygous groups (table 1). Over the 12-yr time period studied, subjects with the $\mathrm{O} / \mathrm{O}$ haplotype also had the fastest annual rate of decline in FEV1 $(2.2 \pm 0.5 \%$ of baseline versus $1.3 \pm 0.1 \%$ in the $\mathrm{A} / \mathrm{A}$ group and $0.7 \pm 0.1 \%$ in the $\mathrm{A} / \mathrm{O}$ group, $\mathrm{p}<0.001$; fig. $2 \mathrm{~b}$ ). Oxygen saturations were significantly $(\mathrm{p}<0.001)$ lower in this group $(93.2 \pm 2.1 \%)$ than in either heterozygotes $(96.0 \pm 0.2 \%)$ or wild-type homozygotes $(96.0 \pm 0.2 \%$; fig. $2 \mathrm{c})$. This was reflected in the requirement for supplementary oxygen, which was highest in the $\mathrm{O} / \mathrm{O}$ group $(\mathrm{O} / \mathrm{O} 20 \%$; A/A 3.7\%; A/O 1.1\%; Fisher's exact test $\mathrm{p}<0.01)$.

Infection and inflammation. The majority of the adult cohort $(86.7 \%)$ had experienced repeated positive cultures for $P$. aeruginosa, but no significant link was observed with $M B L-2$ haplotype; as a result of limited numbers of noninfected individuals, further analysis of this effect on the basis of MBL status was not attempted. A total of 18 of the adults were infected at the time of recruitment with
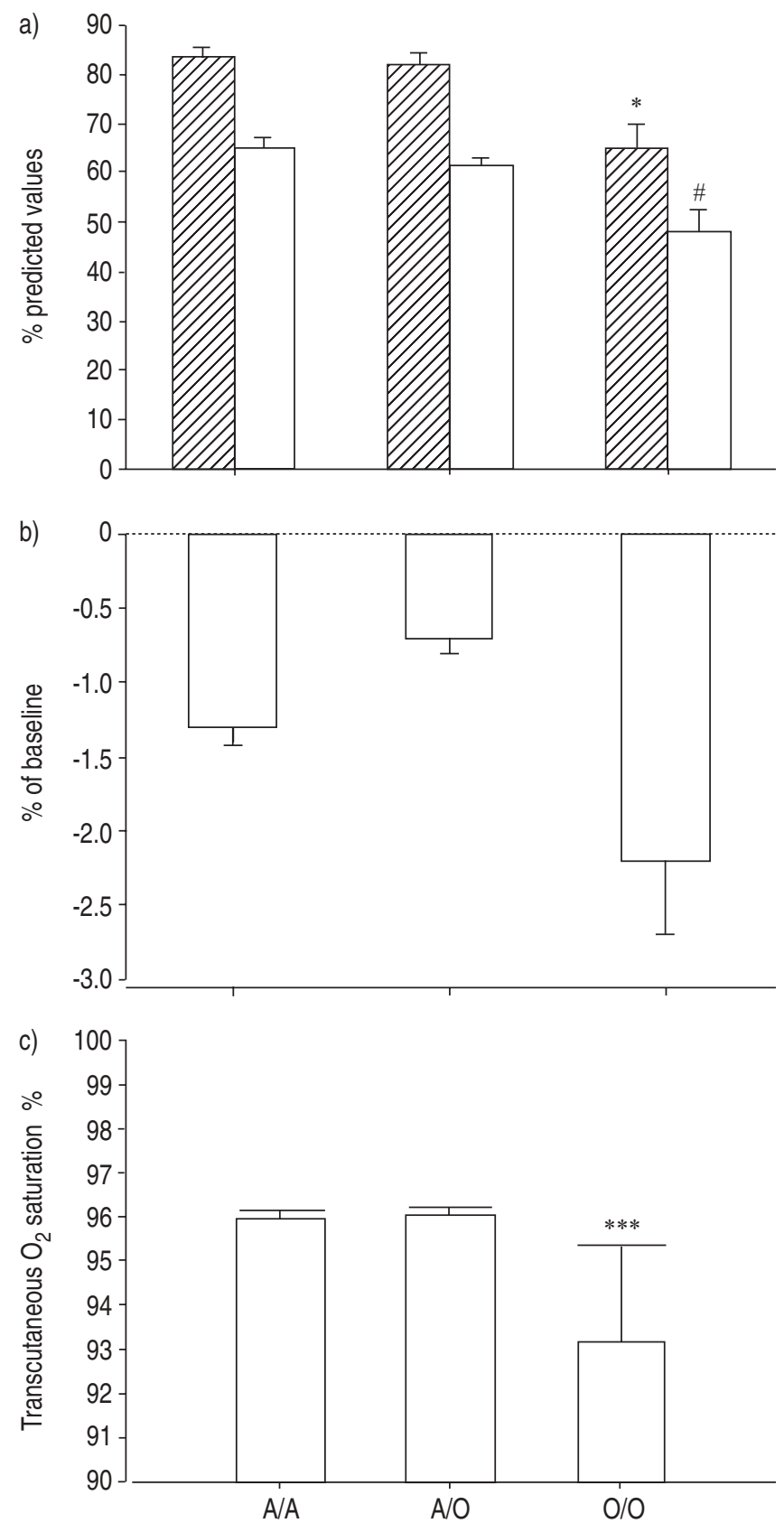

Fig. 2. - a) In adults, both forced expiratory volume in one second $(\mathrm{FEV}$; $\square$ ) and forced vital capacity $(\mathbb{Z})$ were significantly different across the three mannose-binding lectin $(M B L)-2$ haplotype groups (A/A: $\mathrm{n}=163 ; \mathrm{A} / \mathrm{O}: \mathrm{n}=99 ; \mathrm{O} / \mathrm{O}: \mathrm{n}=11$; ANOVA $\mathrm{p}<0.05$ ). The lowest values were seen in subjects with the $\mathrm{O} / \mathrm{O}$ haplotype $(*: \mathrm{p}<0.05$ versus both other groups; \#: $\mathrm{p}<0.05$ versus A/A subjects). The values in heterozygotes were not significantly different from those of wild-type patients. b) Annual rate of decline in FEV1 was calculated on all adult patients with at least two lung function recordings a year apart. Linear regression was performed where three or more recordings were available and the data are expressed as \% decline from baseline values. Rates differed significantly across MBL groups $(\mathrm{p}<0.001)$, with those possessing two mutations demonstrating the fastest decline (A/A: $n=144 ; A / O: n=85 ; O / O: n=11$ ). c) Patients possessing two mutant $M B L-2$ alleles $(\mathrm{O} / \mathrm{O})$ had significantly reduced transcutaneous oxygen saturations (***: $\mathrm{p}<0.001$ versus both other groups; A/A: $\mathrm{n}=145 ; \mathrm{A} / \mathrm{O}: \mathrm{n}=89 ; \mathrm{O} / \mathrm{O}: \mathrm{n}=10$ ).

B. cepacia and a further 38 patients were recruited from other UK centres. No significant effect of $M B L-2$ was observed (infected: A/A $57.1 \%, \mathrm{~A} / \mathrm{O} \quad 39.3 \%$, O/O 3.6\%; 
Table 1.-Effect of the X-promoter polymorphism on mean lung function values in either homozygous or heterozygous adults

\begin{tabular}{llc}
\hline Haplotype groups & FEV1\% & FVC $\%$ \\
\hline A/A & & \\
YA/YA & $61.5 \pm 2.8^{\#}$ & $81.9 \pm 2.5^{\oplus}$ \\
YA/XA & $66.2 \pm 2.7^{\#}$ & $83.3 \pm 2.5^{\oplus}$ \\
XA/XA & $75.1 \pm 8.6^{\#}$ & $91.5 \pm 6.2^{\bullet}$ \\
A/O & $61.2 \pm 2.8^{+}$ & $81.6 \pm 2.5^{+}$ \\
YA/O & $60.1 \pm 3.6^{+}$ & $83.0 \pm 3.4^{+}$ \\
XA/O &
\end{tabular}

Data are presented as mean \pm SEM. FEV1: forced expiratory volume in one second; FVC: forced vital capacity. ${ }^{\#}: \mathrm{p}=0.1 ;{ }^{\uparrow}: \mathrm{p}=0.3{ }^{+}: \mathrm{p}=0.8$.

noninfected: A/A $60.0 \%$, A/O 36.1\%, O/O 3.9\%; p=0.8). In total, $40.1 \%$ of patients had required at least one admission for i.v. antibiotics in 2002; O/O patients had received the greatest number of $i . v$. courses (fig. $3 \mathrm{a} ; \mathrm{p}=0.015$ ). Most recent CRP (obtained at annual assessment) was significantly raised in this group (fig. $3 b ; p<0.05$ ), with a similar trend in total circulating leukocyte count (fig. $3 \mathrm{c} ; \mathrm{p}=0.06$ ).

The clinical disadvantage in the $\mathrm{O} / \mathrm{O}$ group could not be explained by these patients being either significantly older than the other haplotype groups (A/A: 29.3 $\pm 0.7 \mathrm{yrs}, \mathrm{A} / \mathrm{O}$ : $30.4 \pm 0.8 \mathrm{yrs}, \mathrm{O} / \mathrm{O}: 31.4 \pm 3.4 \mathrm{yrs}$; ANOVA $\mathrm{p}=0.5$ ) or by there being an over-representation of patients possessing the $\Delta / \Delta$ CFTR mutation amongst this group (A/A: $50.7 \%$, $\mathrm{A} / \mathrm{O}$ : $43.3 \%$, O/O: $55.6 \%$; Fisher's exact test $\mathrm{p}=0.7)$. However, to confirm the findings, the data from the $11 \mathrm{O} / \mathrm{O}$ subjects was compared with that of A/A controls matched for age, sex and CFTR genotype (table 2). Two A/A subjects were sought for each $\mathrm{O} / \mathrm{O}$ individual; however, in one case of a patient aged $>50$ yrs, only a single sufficiently close match was available. $\mathrm{O} / \mathrm{O}$ subjects had significantly lower mean lung function values than their matched $\mathrm{A} / \mathrm{A}$ counterparts (FEV1: $47.6 \pm 4.8 \%$ versus $66.1 \pm 5.7 \%, \mathrm{p}=0.02$; FVC: $64.8 \pm 4.7 \%$ versus $84.7 \pm 3.4 \%, \mathrm{p}<0.01)$ and significantly higher CRP levels $\left(25.3 \pm 7.2 \mathrm{mg} \cdot \mathrm{L}^{-1}\right.$ versus $\left.10.7 \pm 1.9 \mathrm{mg} \cdot \mathrm{L}^{-1}, \mathrm{p}<0.02\right)$.

Relationship with mannose-binding lectin serum concentration. Despite the close relationship between $M B L-2$ haplotype and $\mathrm{MBL}$ protein levels, there was no direct inverse correlation between the latter and lung function $(p=0.17)$. To explore this discrepancy, lung function was compared between groups divided on the basis of MBL serum level into upper, middle and lower quintiles, where a significant pattern emerged $(\mathrm{p}<0.05$; fig. 4). The highest FEV1 and FVC values were observed in the middle quintile group, with both upper and lower quintile groups demonstrating reduced lung function.

Paediatrics. Lung function. A total of 191 children had their lung function measured on at least one occasion, with the others being too young to perform the manoeuvre. As none of the $\mathrm{O} / \mathrm{O}$ children was $>12$ yrs old, all comparisons were made for lung function obtained between the ages $7-11$ yrs (mean age A/A: $9.7 \pm 0.2 \mathrm{yrs}, \mathrm{A} / \mathrm{O}$ : $9.7 \pm 0.2 \mathrm{yrs}, \mathrm{O} / \mathrm{O}: 8.6 \pm 1.0 \mathrm{yrs}$; ANOVA $\mathrm{p}=0.3)$. Neither mean FEV1 nor FVC was reduced at this stage in children possessing the $\mathrm{O} / \mathrm{O}$ haplotype (fig. 5), and there was no effect of the X-promoter polymorphism (data not shown).

Infection and inflammation. In total, $85.1 \%$ of children had experienced at least one positive culture for $P$. aeruginosa, and, in $28.8 \%$, the organism had a mucoid phenotype suggestive of chronic infection. For the group
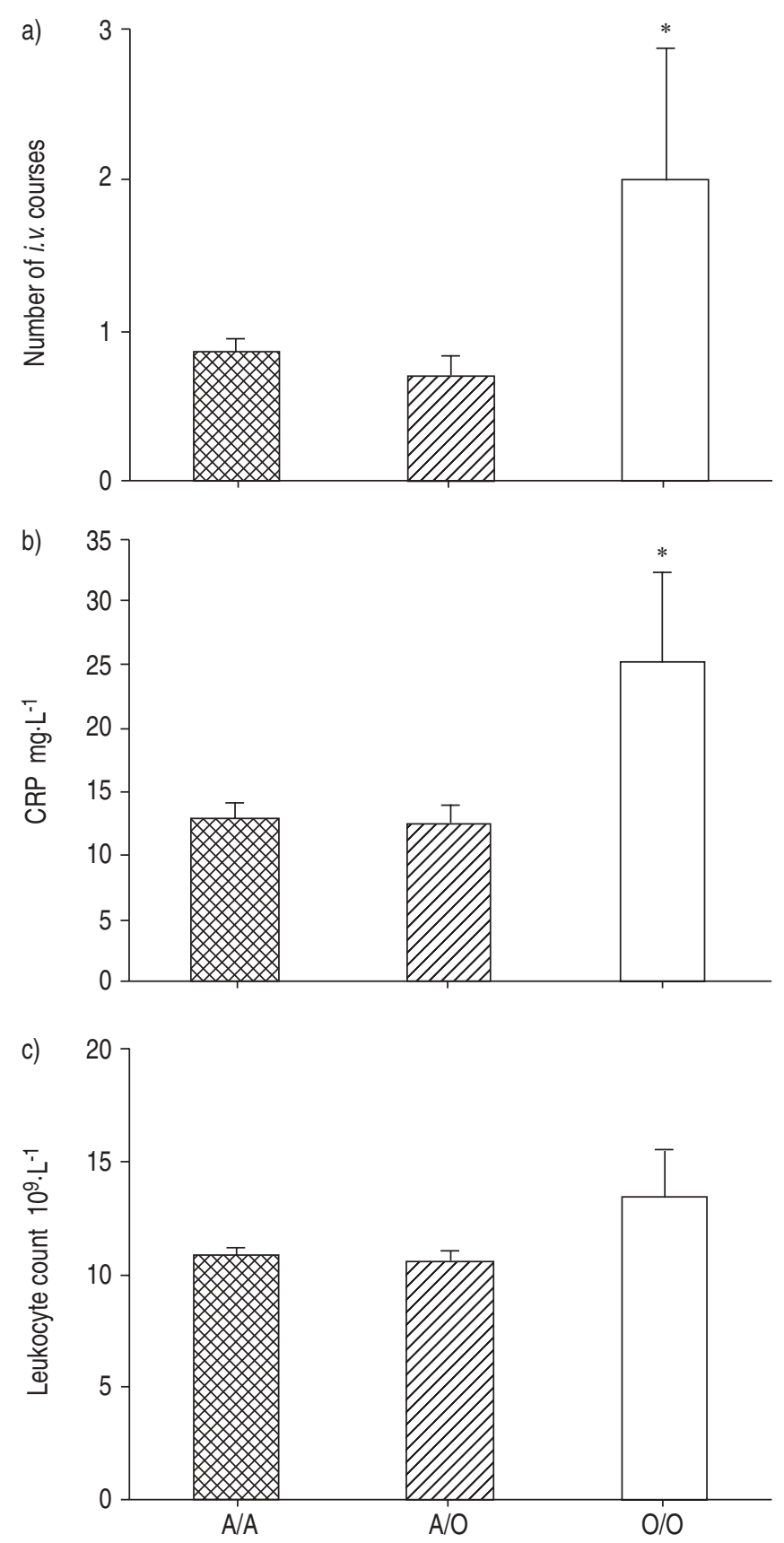

Fig. 3.-a) Mean number of i.v. antibiotic courses in 2002 differed across mannose-binding lectin-2 haplotypes, with the greatest number being received by $\mathrm{O} / \mathrm{O}$ adults $(*: \mathrm{p}<0.05$ compared with both other groups; A/A: $n=166 ; A / O: n=103 ; O / O: n=10)$. b) $O / O$ adult patients had significantly raised C-reactive proteins (CRPs; *: p $<0.05$ compared with both other groups; $\mathrm{A} / \mathrm{A}: \mathrm{n}=166 ; \mathrm{A} / \mathrm{O}: \mathrm{n}=103 ; \mathrm{O} / \mathrm{O}: \mathrm{n}=11$ ). c) A similar trend was seen with regard to peripheral leukocyte count (ANOVA $\mathrm{p}=0.06 ; \mathrm{A} / \mathrm{A}: \mathrm{n}=159 ; \mathrm{A} / \mathrm{O}: \mathrm{n}=100 ; \mathrm{O} / \mathrm{O}: \mathrm{n}=11$ ).

as a whole, infection with $P$. aeruginosa before the first lung function measurement had a significant adverse effect on both FEV1 (87.2 $\pm 1.7 \%$ versus $96.1 \pm 2.2 \% ; \mathrm{p}<0.01)$ and FVC $(95.2 \pm 1.4 \%$ versus $101.3 \pm 2.1 \%$; $=0.02)$. However, there was no association between infection rates, age or mucoid conversion and $M B L-2$ haplotype. By the end of the study, seven children had experienced at least one positive culture for $B$. cepacia. There was no apparent trend with regard to MBL haplotype (YA/YA: $n=3, Y A$ / $\mathrm{XA}: \mathrm{n}=2$, YA/O: $n=1$ and $\mathrm{XA} / \mathrm{O}: \mathrm{n}=1)$. No differences were 
Table 2. - Comparison between A/A and O/O subjects matched for sex, age and cystic fibrosis transmembrane regulator (CFTR) genotype

\begin{tabular}{|c|c|c|c|c|c|c|c|}
\hline Triplet & $M B L-2$ haplotype & Sex & CFTR & Age yrs & FEV1 \% & FVC \% & P. aeruginosa \\
\hline \multirow[t]{3}{*}{1} & $\mathrm{~A} / \mathrm{A}$ & \multirow[t]{3}{*}{ M } & \multirow[t]{3}{*}{$\Delta /-$} & 20 & 60.3 & 80.1 & $\mathrm{~N}$ \\
\hline & $\mathrm{A} / \mathrm{A}$ & & & 20 & 75.5 & 95.6 & $\mathrm{Y}$ \\
\hline & $\mathrm{O} / \mathrm{O}$ & & & 20 & 54.9 & 65.9 & $\mathrm{Y}$ \\
\hline \multirow[t]{3}{*}{2} & $\mathrm{~A} / \mathrm{A}$ & \multirow[t]{3}{*}{ M } & \multirow[t]{3}{*}{$\Delta-$} & 42 & 36.6 & 69.5 & $\mathrm{Y}$ \\
\hline & $\mathrm{A} / \mathrm{A}$ & & & 42 & 86.1 & 104 & $\mathrm{Y}$ \\
\hline & $\mathrm{O} / \mathrm{O}$ & & & 42 & 18.5 & 38.7 & $\mathrm{Y}$ \\
\hline \multirow[t]{3}{*}{3} & $\mathrm{~A} / \mathrm{A}$ & \multirow[t]{3}{*}{$\mathrm{F}$} & \multirow[t]{3}{*}{$\Delta /-$} & 24 & 97.8 & 100.4 & $\mathrm{Y}$ \\
\hline & $\mathrm{A} / \mathrm{A}$ & & & 25 & 60.8 & 92.4 & $\mathrm{Y}$ \\
\hline & $\mathrm{O} / \mathrm{O}$ & & & 24 & 78.0 & 92.8 & $\mathrm{Y}$ \\
\hline \multirow[t]{3}{*}{4} & $\mathrm{~A} / \mathrm{A}$ & \multirow[t]{3}{*}{$\mathrm{F}$} & \multirow[t]{3}{*}{$\Delta / \Delta$} & 29 & 48.0 & 77.5 & $\mathrm{Y}$ \\
\hline & $\mathrm{A} / \mathrm{A}$ & & & 29 & 50.4 & 58.5 & $\mathrm{Y}$ \\
\hline & $\mathrm{O} / \mathrm{O}$ & & & 29 & 37.3 & 54.6 & $\mathrm{Y}$ \\
\hline \multirow[t]{3}{*}{5} & $\mathrm{~A} / \mathrm{A}$ & \multirow[t]{3}{*}{ M } & \multirow[t]{3}{*}{$\Delta / \Delta$} & 22 & 37.8 & 72.3 & $\mathrm{Y}$ \\
\hline & $\mathrm{A} / \mathrm{A}$ & & & 22 & 62.8 & 74.6 & $\mathrm{Y}$ \\
\hline & $\mathrm{O} / \mathrm{O}$ & & & 22 & 53.5 & 74.0 & Y \\
\hline \multirow[t]{3}{*}{6} & $\mathrm{~A} / \mathrm{A}$ & \multirow[t]{3}{*}{$\mathrm{F}$} & \multirow[t]{3}{*}{$\Delta / \Delta$} & 21 & 104.4 & 100.7 & $\mathrm{Y}$ \\
\hline & $\mathrm{A} / \mathrm{A}$ & & & 21 & 99.7 & 99.8 & $\mathrm{Y}$ \\
\hline & $\mathrm{O} / \mathrm{O}$ & & & 21 & 61.6 & 74.9 & $\mathrm{Y}$ \\
\hline \multirow[t]{3}{*}{7} & $\mathrm{~A} / \mathrm{A}$ & \multirow[t]{3}{*}{ M } & \multirow[t]{3}{*}{$\Delta-$} & 37 & 39.3 & 69.0 & Y \\
\hline & $\mathrm{A} / \mathrm{A}$ & & & 39 & 20.7 & 63.4 & $\mathrm{Y}$ \\
\hline & $\mathrm{O} / \mathrm{O}$ & & & 38 & 29.1 & 51.5 & $\mathrm{Y}$ \\
\hline \multirow[t]{2}{*}{8} & $\mathrm{~A} / \mathrm{A}$ & \multirow[t]{2}{*}{$\mathrm{F}$} & \multirow[t]{2}{*}{$\Delta / \Delta$} & 32 & 33.3 & 61.6 & $\mathrm{Y}$ \\
\hline & $\mathrm{O} / \mathrm{O}$ & & & 36 & 40.3 & 56.4 & $\mathrm{Y}$ \\
\hline \multirow[t]{2}{*}{9} & $\mathrm{~A} / \mathrm{A}$ & \multirow[t]{2}{*}{ M } & \multirow[t]{2}{*}{$\Delta / \Delta$} & 44 & 90.6 & 114.5 & $\mathrm{Y}$ \\
\hline & $\mathrm{O} / \mathrm{O}$ & & & 43 & 51.1 & 72.1 & $\mathrm{~N}$ \\
\hline \multirow[t]{3}{*}{10} & $\mathrm{~A} / \mathrm{A}$ & \multirow[t]{3}{*}{ M } & $-/-$ & 19 & 87.2 & 92.5 & $\mathrm{Y}$ \\
\hline & A/A & & & 20 & 110.3 & 96.2 & $\mathrm{~N}$ \\
\hline & $\mathrm{O} / \mathrm{O}$ & & & 19 & 50.6 & 53.4 & Y \\
\hline 11 & $\mathrm{~A} / \mathrm{A}$ & M & $-/-$ & 54 & 76.3 & 82.5 & $\mathrm{Y}$ \\
\hline & $\mathrm{O} / \mathrm{O}$ & & & 51 & 48.5 & 78.8 & $\mathrm{~N}$ \\
\hline & Mean A/A & & & $30.7 \pm 2.3$ & $66.1 \pm 5.7$ & $84.7 \pm 3.4$ & \\
\hline & Mean $\mathrm{O} / \mathrm{O}$ & & & $31.4 \pm 3.4^{\#}$ & $47.6 \pm 4.8^{\top}$ & $64.8 \pm 4.7^{+}$ & \\
\hline
\end{tabular}

MBL: mannose-binding lectin; FEV1: forced expiratory volume in one second; FVC: forced vital capacity; P. aeruginosa: Pseudomonas aeruginosa; M: male; F: female; $\Delta: \Delta \mathrm{F} 508$; -: other mutation; $\mathrm{N}$ : no; Y: yes. ${ }^{\#}: \mathrm{p}=0.9 ;{ }^{\top}: \mathrm{p}=0.02 ;{ }^{+}: \mathrm{p}<0.01$, compared with matched $\mathrm{A} / \mathrm{A}$ counterparts.

observed between $M B L-2$ haplotype groups with regard to ever having been admitted for i.v. antibiotics or age at first admission (data not shown). Neither current CRP nor white blood cell count was significantly different across the three groups (data not shown).

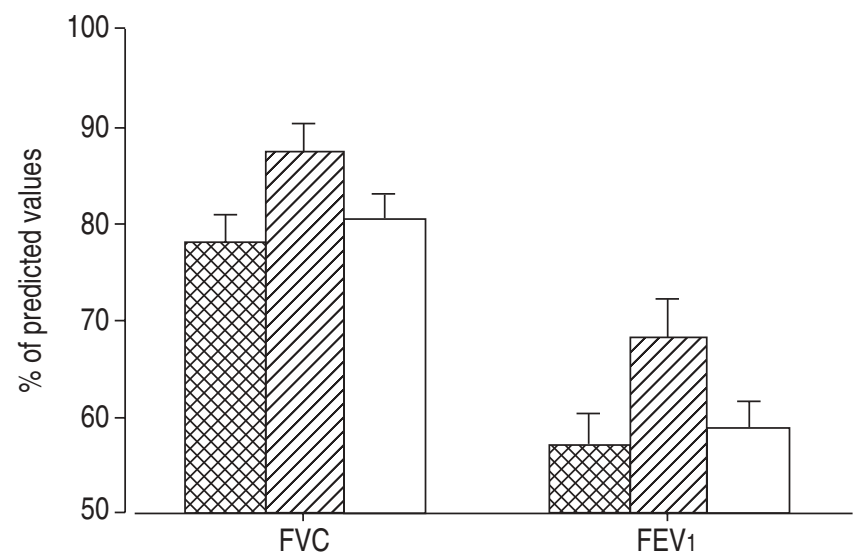

Fig. 4. - To examine the relationship between mannose-binding lectin levels and lung function, adult patients were divided into groups based on upper $(\mathbf{D})$, middle $(\mathbb{Z})$ and lower $(\square)$ quintiles for serum level. Significant differences were seen for both forced expiratory volume in one second $\left(\mathrm{FEV}_{1} ; \mathrm{p}<0.05\right)$ and forced vital capacity (FVC; $\mathrm{p}=0.02$ ), with the highest lung function observed in patients in the middle quintile group.

\section{Discussion}

In the largest group of $\mathrm{CF}$ patients studied to date, the current authors report that adults possessing two abnormal structural $M B L-2$ alleles have significantly reduced lung function, lower oxygen saturations and an increased

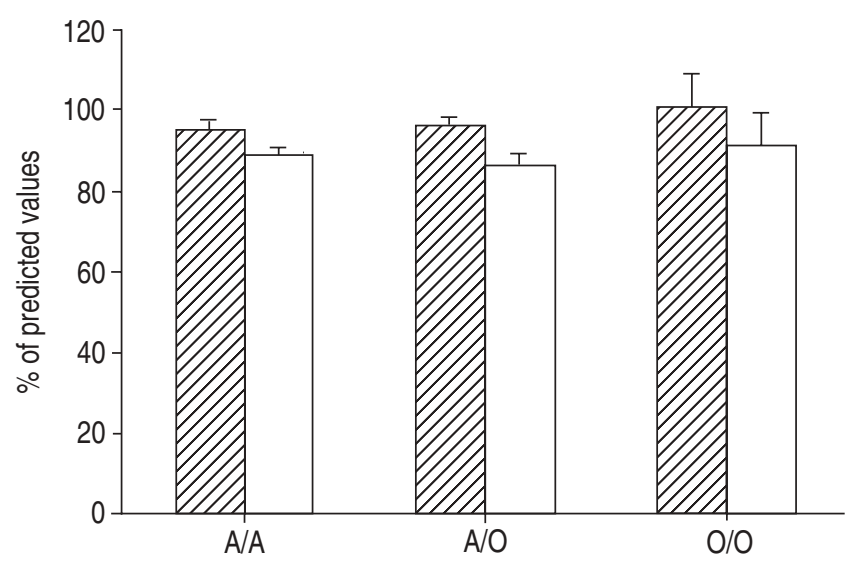

Fig. 5. - No significant effect of mannose-binding lectin-2 genotype was seen on forced expiratory volume in one second $(\square)$ and forced vital capacity $(\mathbb{Z})$ between the ages $7-11$ yrs (all recordings were presented as means for each individual). A/A: $n=113 ; A / O: n=67 ; O / O$ : $\mathrm{n}=6$. 
requirement for hospital admission. This may relate to increased levels of inflammation, as CRP was raised, but appears not to be as a result of chronic bacterial infection. These associations were not seen during childhood, which may raise issues relating to the sequence of progression of $\mathrm{CF}$ lung disease or to the timing of modifier-gene studies.

Two previous studies have examined the effect of MBL status on lung function in $\mathrm{CF}[2,3]$. As in these studies, the MBL-deficient $\mathrm{O} / \mathrm{O}$ group in the present study is small, but similar findings in each of the studies lend strength to the conclusions. GABOLDE et al. [3] matched 11 MBL-deficient adults $(\mathrm{O} / \mathrm{O})$ with homozygous sufficient controls (A/A), and reported that MBL deficiency led to significantly worse lung function. No disadvantage was seen in heterozygotes. In contrast, GARRED et al. [2] reported that either one or two structural $M B L-2$ gene mutations $(\mathrm{A} / \mathrm{O}$ or $\mathrm{O} / \mathrm{O})$ led to the impairment of FEV1 and reduced survival. The current lung function findings concur with the study by GABOLDE et al. [3], as it is clearly shown in this large group of adults that structural heterozygotes have normal lung function. This is despite the current observation that a number of the heterozygotes have MBL protein levels within the range seen in patients with two variant alleles.

Wild-type MBL is polymeric in nature with 4-6 subunits, each based on three identical peptide chains associated through a collagenous triple helix. $M B L-2$ structural gene mutations impair this polymerisation, so that patients possessing two mutated structural alleles do not possess this form of the protein [17]. However, in individuals with apparently low or absent levels of wild-type MBL, a low molecular weight monomeric form can exist [18], and may circulate at high levels in some individuals [19]. This monomeric form of $\mathrm{MBL}$ is not usually detected by commonly used assays, such as that utilised in the present study [20]. Whilst the functionality of this form of MBL is unknown, the current results indicate that either small quantities of wild-type MBL, which may be seen in XA/YO individuals, or high levels of monomeric MBL, which may be seen in $\mathrm{YO} / \mathrm{YO}$ individuals, may be critical in determining the lung function of patients with $\mathrm{CF}$.

How MBL is operating in $\mathrm{CF}$ is still unclear. In contrast to GABOLDE et al. [3], the current authors are in agreement with GARRED et al. [2] that MBL does not influence susceptibility to $P$. aeruginosa or B. cepacia. This is despite results from the current authors' earlier in vitro study demonstrating high levels of MBL binding to clinical isolates of B. cepacia and subsequent activation of complement [21]. Taken together, these findings might suggest that complement-mediated clearance of bacteria is not an important mechanism of action for $\mathrm{MBL}$ in the $\mathrm{CF}$ lung. Nevertheless, levels of binding that are insufficient to activate complement-mediated bacterial killing may be sufficient to modulate the host inflammatory response to a microbial insult, and the present study provides some clinical evidence to suggest that this may be the case in CF. MBL plays a complex and incompletely understood role in the inflammatory response [5]. Low circulating protein levels have been found to be both advantageous and detrimental in different disease settings [22, 23], and a biphasic dose response has been demonstrated in vitro [5]. It would appear from the current data that MBL, which is present in the airway surface fluid (ASF), may be exerting an anti-inflammatory action. In addition to the much lower levels of circulating protein available to reach the airways in $\mathrm{O} / \mathrm{O}$ individuals, recent data suggest that the mutant forms of the protein may be more susceptible to degradation by matrix metalloproteinases that are present in abundance in the CF ASF [24], and, thus, MBL-deficient individuals may be doubly compromised. The current authors are examining this hypothesis further by measuring levels of MBL and inflammatory cytokines directly in CF bronchoalveolar lavage samples.

Two important issues relating to the study of modifier genes in CF have been raised by the present study. The first concerns the apparently different results obtained from our paediatric and adult cohorts. It is recognised that the group of $\mathrm{O} / \mathrm{O}$ children was very small $(\mathrm{n}=6)$, and, thus, this study may have been underpowered to detect a difference in children. This is a recurring problem in modifier-gene studies attempting to examine the effect of fairly rare genotypes. No trends were visible, but the current authors have begun the collection of samples from another paediatric cohort in order to increase numbers. In addition, whilst it is possible that there may be disease stage-specific effects of modifier genes, it is equally likely that any effects are more difficult to detect in the younger age group. Whilst GARRED et al. [2] observed an MBL effect in individuals as young as 8 yrs old, most of the children in this study had well-preserved lung function, and low or undetectable levels of systemic inflammatory markers. Thus, with the clinical markers used in this study, any potential modifier gene must exert a very significant detrimental effect before that effect will be apparent, even in a relatively large cohort, such as that of the current authors. This may be become increasingly difficult, as children and adults with CF have significantly better health status than was usual in previous decades [25]. Future modifier-gene studies should possibly be conducted initially in adults, in whom the greater variability in severity might facilitate the identification of groups at risk. Alternatively, more sensitive clinical markers, such as, in this case, direct measures of airway inflammation, may be more useful. The second important point relates to the ability to differentiate cause from effect when conducting studies on proteins involved in inflammation or acute-phase response processes. Patients with the lowest serum MBL levels had low lung function. However, patients with the highest levels also had lower lung function than those with intermediate levels. It is hypothesised that, whilst the former group were demonstrating poor lung function as a result of MBL deficiency, the latter group had high protein levels in response to their poor pulmonary status. This hypothesis is supported by the finding that wild-type (homozygous sufficient) adults had significantly higher MBL levels than the corresponding group of children. This is likely to be the group with the greatest capacity for increasing protein levels in response to stimuli, and the higher levels are likely to reflect the more advanced disease status with increasing age. Follow-up studies in the younger patients may help to confirm this hypothesis. It is suggested that grouping on the basis of nonvariable parameters, such as genotype rather than variable protein levels, may be more likely to yield clear, interpretable results.

In addition to the increased understanding they provide of disease pathogenesis, modifier-gene studies are being conducted with a view to the development of novel forms of therapy. Purified serum-derived mannose-binding lectin has already been administered to patients, including one with cystic fibrosis who appeared to benefit [26]. With the advances in recombinant protein technology, mannose-binding lectin may become a treatment option for deficient patients suffering from a variety of diseases. Whilst the current data indicated that the detrimental effect in this disease is limited to those patients with two abnormal copies of the mannosebinding lectin- 2 gene (3- $4 \%$ of cystic fibrosis patients), further studies are required to examine the potential role of mannosebinding lectin therapy in cystic fibrosis. 


\begin{abstract}
Acknowledgements. The authors would like to acknowledge the patients and parents for consenting to the study; M. Hodson for allowing access to the clinical database; S. Elborn, S. Conway and D. Bilton for providing samples from B. cepacia-infected adult patients; M. Festing for statistical advice; J. Francis and colleagues in the Paediatric $\mathrm{CF}$ clinic for administrative assistance; and L. Somerton, S. Escudera Garcia and the staff of the Clinical Microbiology Laboratory at the Royal Brompton Hospital, London, UK, for technical support.
\end{abstract}

\section{References}

1. Koch C, Hoiby N. Pathogenesis of cystic fibrosis. Lancet 1993; 341: 1065-1069.

2. Garred P, Pressler T, Madsen HO, et al. Association of mannose-binding lectin gene heterogeneity with severity of lung disease and survival in cystic fibrosis. J Clin Invest 1999; 104: 431-437.

3. Gabolde M, Giulloud-Bataille M, Feingold J, Besmond C. Association of variant alleles of mannose binding lectin with severity of pulmonary disease in cystic fibrosis: cohort study. BMJ 1999; 319: 1166-1167.

4. Turner MW. Mannose-binding lectin (MBL) in health and disease. Immunobiology 1998; 199: 327-339.

5. Jack DL, Read RC, Tenner AJ, Frosch M, Turner MW, Klein NJ. Mannose-binding lectin regulates the inflammatory response of human professional phagocytes to Neisseria meningitidis serogroup B. J Infect Dis 2001; 184: 1152-1162.

6. Lipscombe RJ, Sumiya M, Hill AV, et al. High frequencies in African and non-African populations of independent mutations in the mannose binding protein gene. Hum Mol Genet 1992; 1: 709-715.

7. Madsen HO, Garred P, Kurtzhals JA, et al. A new frequent allele is the missing link in the structural polymorphism of the human mannan-binding protein. Immunogenetics 1994; 40: $37-44$.

8. Madsen HO, Garred P, Thiel S, et al. Interplay between promoter and structural gene variants control basal serum level of mannan-binding protein. J Immunol 1995; 155: 3013-3020.

9. Summerfield JA, Sumiya M, Levin M, Turner MW. Association of mutations in mannose binding protein gene with childhood infection in consecutive hospital series. $B M J$ 1997; 314: 1229-1232.

10. Hibberd ML, Sumiya M, Summerfield JA, Booy R, Levin M. Association of variants of the gene for mannose-binding lectin with susceptibility to meningococcal disease. Meningococcal Research Group. Lancet 1999; 353: 1049-1053.

11. Garred P, Madsen HO, Balslev U, et al. Susceptibility to
HIV infection and progression of AIDS in relation to variant alleles of mannose-binding lectin. Lancet 1997; 349: 236-240.

12. Koch A, Melbye M, Sorensen $\mathrm{P}$, et al. Acute respiratory tract infections and mannose-binding lectin insufficiency during early childhood. JAMA 2001; 285: 1316-1321.

13. Garred P, Brygge K, Sorensen CH, Madsen HO, Thiel S, Svejgaard A. Mannan-binding protein: levels in plasma and upper-airways secretions and frequency of genotypes in children with recurrence of otitis media. Clin Exp Immunol 1993; 94: 99-104.

14. Rosenthal M, Bain SH, Cramer D, et al. Lung function in white children aged 4 to 19 years: spirometry. Thorax 1993; 48: 794-802.

15. Jack D, Bidwell J, Turner MW, Wood N. Simultaneous genotyping for all three known structural mutations in the human mannose-binding lectin gene. Hum Mutat 1997; 9: $41-46$.

16. Turner MW, Dinan L, Heatley S, et al. Restricted polymorphism of the mannose-binding lectin gene of indigenous Australians. Hum Mol Genet 2000; 9: 1481-1486.

17. Madsen HO, Satz ML, Hogh B, Svejgaard A, Garred P. Different molecular events result in low protein levels of mannan-binding lectin in populations from southeast Africa and South America. J Immunol 1998; 161: 3169-3175.

18. Lipscombe RJ, Sumiya M, Summerfield JA, Turner MW Distinct physicochemical characteristics of human mannose binding protein expressed by individuals of differing genotype. Immunology 1995; 85: 660-667.

19. Garred P, Larsen F, Madsen HO, Koch C. Mannose-binding lectin deficiency: revisited. Mol Immunol 2003; 40: 73-84.

20. Turner MW, Johnson M, Booth C, Klein N, Rolland J, Davies J. Assays for human mannose-binding lectin. J Immunol Methods 2003; 276: 147-149.

21. Davies J, Neth O, Alton E, Klein N, Turner M. Differential binding of mannose-binding lectin to respiratory pathogens in cystic fibrosis. Lancet 2000; 355: 1885-1886.

22. Garred P, Madsen HO, Marquart $\mathrm{H}$, et al. Two edged role of mannose binding lectin in rheumatoid arthritis: a cross sectional study. J Rheumatol 2000; 27: 26-34.

23. Garred $\mathrm{P}$, Richter $\mathrm{C}$, Andersen $\mathrm{AB}$, et al. Mannan-binding lectin in the sub-Saharan HIV and tuberculosis epidemics. Scand J Immunol 1997; 46: 204-208.

24. Butler GS, Sim D, Tam E, Devine D, Overall CM. Mannosebinding lectin (MBL) mutants are susceptible to matrix metalloproteinase proteolysis: potential role in human MBL deficiency. J Biol Chem 2002; 277: 17511-17519.

25. Elborn JS, Shale DJ, Britton JR. Cystic fibrosis: current survival and population estimates to the year 2000. Thorax 1991; 46: 881-885.

26. Garred P, Pressler T, Lanng S, et al. Mannose-binding lectin (MBL) therapy in an MBL-deficient patient with severe cystic fibrosis lung disease. Pediatr Pulmonol 2002; 33: 201207. 